\title{
LOGISTICS INTEGRATION PROCESSES IN THE FOOD INDUSTRY
}

\author{
CRISTINA GIMÉNEZT \\ GREL-IET; Universitat Pompeu Fabra*
}

\begin{abstract}
This paper analyses the integration process that firms follow to implement Supply Chain Management (SCM). This study has been inspired in the integration model proposed by Stevens (1989). He suggests that companies internally integrate first and then extend integration to other supply chain members, such as customers and suppliers.

To analyse the integration process a survey was conducted among Spanish food manufacturers. The results show that there are companies in three different integration stages. In stage I, companies are not integrated. In stage II, companies have a medium-high level of internal integration in the Logistics-Production interface, a low level of internal integration in the Logistics-Marketing interface, and a medium level of external integration. And, in stage III, companies have high levels of integration in both internal interfaces and in some of their supply chain relationships.
\end{abstract}

\section{Key words}

Supply Chain Management, Food industry, Logistics integration process.

\section{JEL codes}

L290, L660, M100, M110

\footnotetext{
T The author thanks the members of GREL-IET for their comments and suggestions.

* Cristina Giménez Thomsen. Departament d'Economia I Empresa. UPF. Ramon Trias Fargas, 25-27. 08005 Barcelona, Spain. Phone: 34-935422901. Fax: 34-935421746. E-mail: cristina.gimenez@upf.edu.
} 


\section{Introduction}

The process industries cover a wide range of businesses and realize a considerable portion of GDP in many countries. However, few Operations Management research has paid attention to this type of industries. The aim of this paper is to analyse the Supply Chain Management (SCM) implementation model in a particular process industry: the food manufacturing.

Integration along the supply chain is a topic of interest and importance among logistics managers and researchers because it has been considered a source of better supply chain performance (Shapiro, 1984; Scott \& Westbrook, 1991; Byrne \& Javad, 1992; Gustin, Stank \& Daugherty, 1994; The Global Research Team at Michigan State University, 1995; Christopher, 1998; Cooper, 1993; Ellram \& Cooper, 1993; and Christiansee \& Kumar, 2000) and competitive advantage (Christopher, 1998). However, few empirical studies analyse the integration process (Stank, Keller \& Daugherty, 2001; and Gimenez \& Ventura, 2003).

During the 1990's some companies initiated an integration process through the implementation of the SCM approach. SCM is "the integration of key business processes from end user through original suppliers that provides products, services, and information that add value for customers and other stakeholders" (Lambert, Cooper \& Pagh, 1998). This integrative philosophy involves internal and external integration. Internal integration refers to the coordination, collaboration and integration of Logistics with other functional areas, while external integration refers to the integration of a firm's logistics activities with those of their customers and suppliers (Stock, Greis \& Kasarda, 1998).

Stevens (1989) suggests that companies integrate internally first, and then, extend integration to other supply chain members. Companies usually follow an integration 
process that goes through three different stages. In stage I, there is no integration. In stage II companies are internally integrated: their logistics activities are integrated with the activities of other functional units, such as Purchasing, Production and Marketing. And, in stage III, the internal integration achieved in stage II is extended to other supply chain members, such as customers and suppliers.

The objectives of this paper are: (1) to analyse the integration process (internal external integration); (2) to compare the integration in the Logistics-Production interface with the integration in the Logistics-Marketing interface, and (3) to explore the integration stage of Spanish food manufacturers.

Our contribution to the existing body of knowledge on integration topics is to obtain an in depth knowledge of the integration process, comparing two levels of internal integration (Logistics-Marketing and Logistics-Production) and analysing the relationship between these internal integration levels and the level of external integration. We will describe the integration model that Spanish food manufacturers are following.

The remainder of the paper is structured as follows. Section two briefly examines the literature on logistics' integration topics; section three describes the research methodology; section four presents the research results and section five draws the conclusions and managerial implications from this work.

\section{Literature review}

\subsection{Previous logistics' integration research}

Many studies consider internal or external integration from the logistics' point of view (Daugherty, Sabath, \& Rogers, 1992; Larson, 1994; Daugherty, Ellinger \& Rogers, 1995; Groves \& Valsamakis, 1998; Stank, Crum \& Arango, 1999; Stank, Daugherty \& 
Autry, 1999; Ellinger, Daugherty \& Keller, 2000; Ellinger, Taylor \& Daugherty, 2000; Scannell, Vickery. \& Dröge, 2000; and Stank, Daugherty \& Ellinger, 2000), but very few consider both integration levels simultaneously (Stank, Keller \& Daugherty, 2001; Gimenez \& Ventura, 2003 and 2003b).

The studies of Stank, Keller \& Daugherty (2001) and Gimenez \& Ventura (2003 and 2003b) share a common aim: to analyse the impact of internal and external integration on performance. The integration-performance models of these authors included also a relationship between the levels of internal and external integration. All of them found that these levels of integration are positively correlated. This suggests that they positively influence each other.

Our study follows a similar framework to the one used by Stank, Keller \& Daugherty (2001) and Gimenez \& Ventura (2003 and 2003b), but it differs from them in some points:

- Stank, Keller and Daugherty (2001) conducted a multi-industry analysis to study the relationship between integration and performance, while we consider the integration process of companies that belong to the same industry. Other differences between this study and ours are: first, they consider a unique level of internal integration, while we compare the integration achieved in two internal interfaces (Logistics-Marketing and Logistics-Production). And, second, they consider a unique level of external integration for each firm, while we consider that the level of external integration has to be related to a particular relationship (of the firm) and not to the firm itself.

- Gimenez \& Ventura (2003 and 2003b) conducted a survey in the Spanish grocery sector to analyse the integration-performance relationship. While the first paper (Gimenez \& Ventura, 2003) only considers internal integration in the 
Logistics-Production interface, the second one (Gimenez \& Ventura, 2003b) considers two internal interfaces (Logistics-Production and Logistics-Marketing), as we do in this study. Regarding the level of external integration, we share their approach: to relate the level of external integration to particular relationships and not to the firm itself. The main difference between the works of Gimenez \& Ventura (2003 and 2003b) and this paper is that they analyse if there is any relationship between the level of internal and external integration without studying the integration process itself, while we focus on the integration process.

\subsection{The integration model}

This paper considers internal and external integration. Internal integration refers to the coordination, collaboration and integration of Logistics with other functional areas (Stock, Greis \& Kasarda, 1998). This paper considers internal integration in two different interfaces: Logistics-Marketing and Logistics-Production. We consider these interfaces for two reasons: first, the coordination between these areas is vital to produce and serve what customers demand, how and when they want. And, second, Logistics is an organizational function which shares responsibilities with Marketing and Production (Casanovas \& Cuatrecasas, 2001). The combination of the integration levels achieved in these two interfaces are shown in figure 1. At one extreme is a strategy of little or no integration (Option 1). At the other end of the continuum is a strategy with high levels of integration in both internal interfaces: Logistics-Marketing and Logistics-Production (Option 4). And, in between these polar extremes are companies whose strategies involve integration in the Logistics-Marketing interface (Option 3) or the Logistics-Production interface (Option 2). 
Figure 1. Internal integration

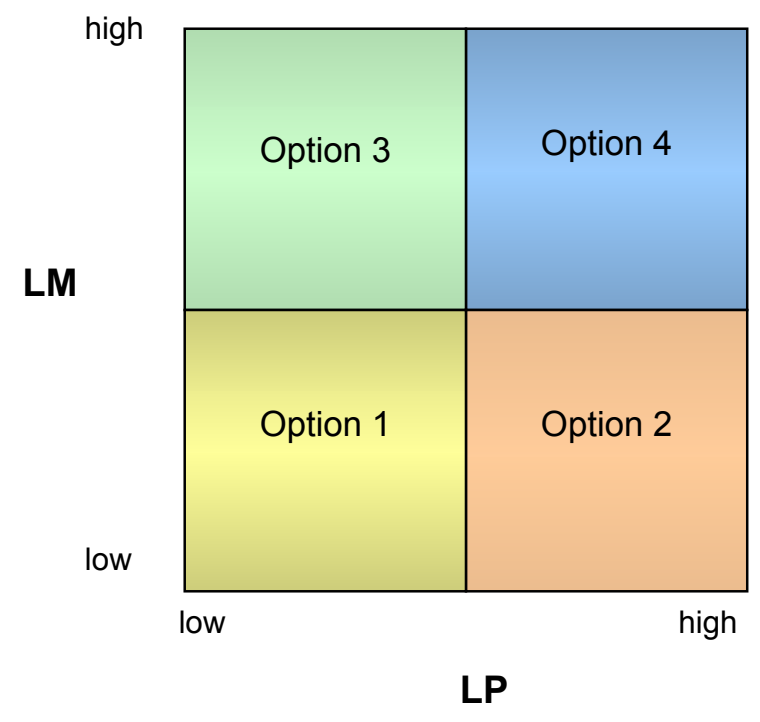

External integration refers to the integration of a firm's logistics activities with those of their customers and suppliers (Stock, Greis \& Kasarda, 1998). When external integration is considered, the model shown in figure 1 is transformed into the model shown in figure 2, where the height represents the level of external integration.

Figure 2. Internal and external integration

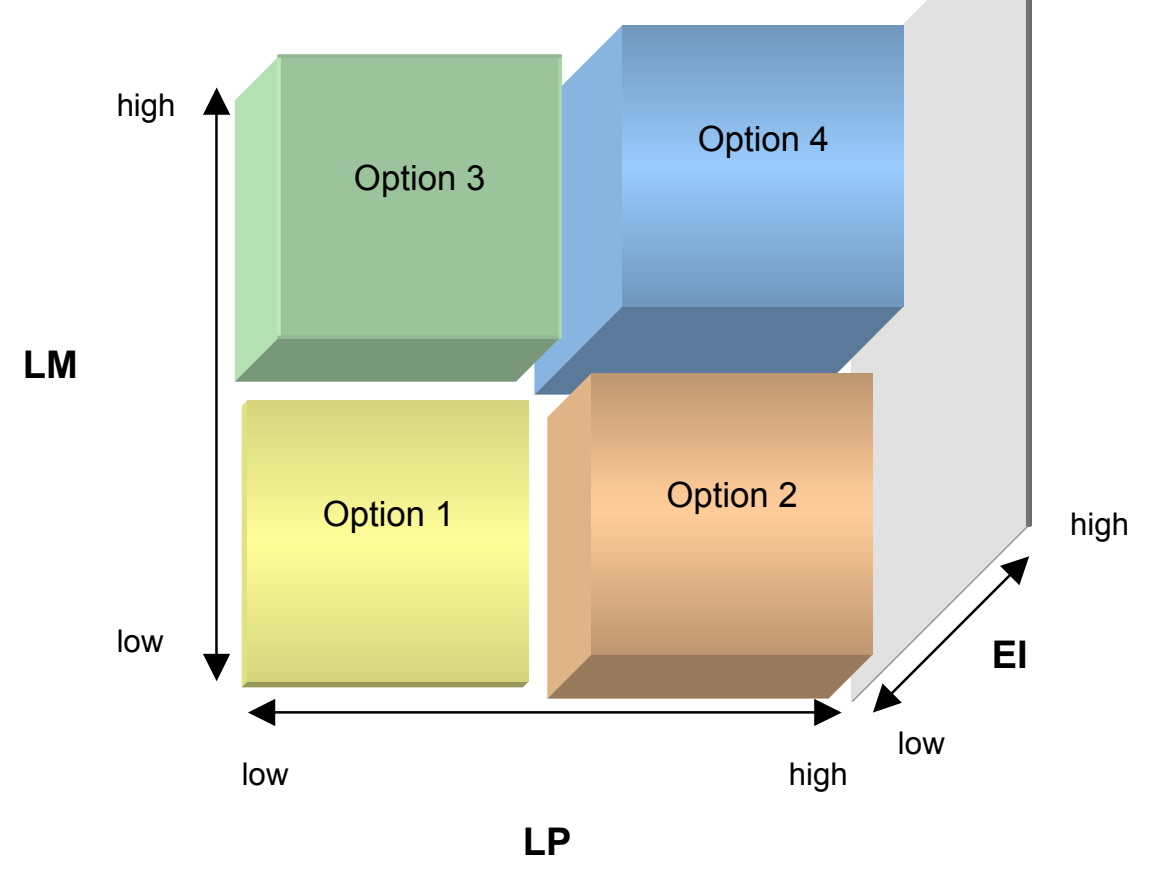


The first set of hypotheses relates to the interrelationship of internal and external collaboration. The literature suggests that firms must achieve a relatively high degree of collaboration among internal processes before initiating supply chain arrangements (Stevens, 1989). The inability to integrate fully within the firm's logistics operations is a leading cause of strategic alliance failure. Breakdowns in internal collaboration inhibit delivery of promised performance levels (The Global Logistics Team at Michigan State University, 1995).

Hypothesis H1a. Firms must achieve a relatively high degree of collaboration among internal processes before initiating external integration.

However, interviews we conducted in preparation for this research raised concerns regarding this relationship. One leading FMCG (Fast Moving Consumer Good) manufacturer had initiated an external integration arrangement with one grocery retailer without being internally integrated. This case leads us to the following hypothesis:

Hypothesis $\mathrm{H} 1 \mathrm{~b}$. Firms must achieve a relatively high degree of external integration before initiating internal integration.

Stevens (1989) suggests that external integration is an extension of the internal integration achieved in a previous stage. Accordingly, companies with a low internal integration strategy (Option 1) should present a low level of external integration and companies implementing the full internal integration strategy (Option 4) should have the highest levels of external integration. And, given the partial nature of the internal integration achieved by companies implementing Options 2 and 3, the level of external integration of these companies should logically fall between the low internal integration (Option 1) and full internal integration (Option 4) approaches. These arguments lead to the following set of hypotheses: 
Hypothesis $\mathrm{H} 2 \mathrm{a}$. Companies adopting a full internal integration strategy (Option 4) will have the highest levels of external integration.

Hypothesis H2b. Companies adopting either a Logistics-Production (Option 2) or a Logistics-Marketing (Option 3) integration strategy will have medium levels of external integration.

Hypothesis H2c. Companies adopting a low internal integration strategy (Option 1) will have the lowest levels of external integration.

\section{Methodology}

\subsection{Data collection}

The survey was developed in two stages. First, we identified relevant measures of internal and external integration. And, then, we held a series of meetings with logistics professors and logistics managers to gauge the content and face validity of the survey.

Data were collected from a sample of Spanish manufacturers of the food sector. These companies were selected from the Spanish data base "Fomento de la Producción 25.000 empresas". We restricted ourselves to the food manufacturers and chose those companies with a sales figure in 1999 equal to or higher than 30 million euros. The resulting sample had 172 companies. By sampling an entire country, the research controlled for many confounding factors like telecommunications infrastructure, costs and the overall economy. And, by focusing only on one industry we controlled for other confounding factors, such as the level of implementation of SCM in the industry (there are industries, such as the automotive, where SCM has been implemented for years), the level of competence and the industry's environment. 
The data collection was conducted during the spring-summer of year 2001. Given the strategic focus of the research, it was decided to mail the questionnaire to the Logistics or Supply Chain executive of each firm. The industry breakdown of the sample is shown in Table 1. As early notification of prospective respondents is believed to increase response rates (Fox, Crask \& Kim, 1988), we decided to telephone each firm and ask for their participation in the study. From the 172 companies, only one company refused to participate in the study. The total number of complete questionnaires was 51, which represents a $29,82 \%$ response rate. Potential participants were asked to provide sensitive and confidential data, so the response rate of $29,82 \%$ is considered very satisfactory, especially when compared to the response rate of other studies. For example, Groves \& Valsamakis (1998) used data from a survey with a response rate of 15\%; Stank, Daugherty \& Autry (1999) worked with a 20,2\% response rate, and Stank, Keller \& Daugherty (2001) worked with a $11,5 \%$ response rate.

Table 1. Sample breakdown for manufacturers by sector

\begin{tabular}{lcc}
\hline SAMPLE CHARACTERISTICS & \\
\hline Sales volume (million $€$ ) & \multicolumn{2}{c}{} \\
More than 600 & 0 & $1,96 \%$ \\
$401-600$ & 7 & $13,73 \%$ \\
$201-400$ & 20 & $39,22 \%$ \\
$101-200$ & 13 & $25,49 \%$ \\
$51-100$ & 10 & $19,61 \%$ \\
$30-50$ & \multicolumn{3}{|c}{} \\
\hline Sectors & 6 & $11,76 \%$ \\
Food - Fish and preserved products & 5 & $9,80 \%$ \\
Food - Dairy products & 4 & $7,84 \%$ \\
Food - Wheat & 2 & $3,92 \%$ \\
Food - Dried fruit & 5 & $9,80 \%$ \\
Food - Meats & 2 & $3,92 \%$ \\
Food - Preserved vegetables & 15 & $29,41 \%$ \\
Food - Drinks & 4 & $7,84 \%$ \\
Food - Oils & 8 & $15,69 \%$ \\
Food - Varied products & \multicolumn{2}{c}{} \\
\hline
\end{tabular}


We conducted an analysis of non-response bias based on the procedure described in Armstrong and Overton (1977) and Lambert and Harrington (1990). We numbered the responses sequentially, in the order they were received, and compared late responses with early responses. No noticeable pattern among the variables could be detected to indicate the existence of a non-response bias. Accordingly, non-response bias is unlikely to be an issue in interpreting the results of this study.

\subsection{Scale development}

Respondents were asked to rate on multi-item scales their degree of internal integration in the Logistics-Production and Logistics-Marketing interfaces, and their level of external integration in two supply chain relationships. Internal integration was considered in these two interfaces because, as stated before, the coordination between them is vital to produce and serve what customers demand, how and when they want. And, external integration was analysed for particular relationships because we consider that companies usually strategically segment their relationships (Kraljic, 1983; Copacino, 1990; Anderson and Narus, 1991; Cooper and Gardner, 1993, Dyer, Cho and Chu, 1998; Tang, 1999, Masella and Rangone, 2000) and establish high collaborating relationships with some supply chain members and arm's length relationships with others. Therefore, each firm was asked to think about two manufacturer-retailer relationships. The first relationship was supposed to be the most collaborating one, and the second the least collaborating relationship.

Table 2 shows the items used to measure the levels of integration. These scales were ground in the literature (Ellinger, Daugherty \& Keller, 2000; Stank, Daugherty \& Ellinger, 2000) and exploratory and confirmatory factor analyses were used to ensure reliability. All scales were unidimensional using principal components, except internal integration in the Logistics-Production interface (IILP). The exploratory factor analysis 
(shown in Appendix A) showed that IILP1 was related with a different factor. As a result, the first proposed measure for internal integration in the Logistics-Production interface (IILP1) was discarded. The scales were summed averages of the measurement items and reliability (see Cronbach's $\alpha$ in Table 3) was very satisfactory. Table 3 also shows the measures' Pearson correlation.

Table 2. Variables

\section{VARIABLES}

Internal Integration Logistics-Production (scale of 1 to 10)

IILP1: Informal teamwork

IILP2: Shared ideas, information and other resources

IILP3: Established teamwork

IILP4: Joint planning to anticipate and resolve operative problems

IILP5: Joint establishment of objectives

IILP6: Joint development of the responsibilities' understanding

IILP7: Joint decisions about ways to improve cost efficiencies

Internal Integration Logistics-Marketing (scale of 1 to 10)

IILM1: Informal teamwork

IILM2: Shared ideas, information and other resources

IILM3: Established teamwork

IILM4: Joint planning to anticipate and resolve operative problems

IILM5: Joint establishment of objectives

IILM6: Joint development of the responsibilities' understanding

IILM7: Joint decisions about ways to improve cost efficiencies

External Integration (scale of 1 to 10 )

El1: Informal teamwork

EI2: Shared information about sales forecasts, sales and stock levels

El3: Joint development of logistics processes

El4: Established work team for the implementation and development of continuous replenishment programs (CRP) or other ECR practice

EI5: Joint planning to anticipate and resolve operative problems

El6: Joint establishment of objectives

El7: Joint development of the responsibilities' understanding

El8: Joint decisions about ways to improve cost efficiencies

Source: Internal integration variables were adopted from the literature (Ellinger, Daugherty Keller, 2000; Stank, Daugherty \& Ellinger, 2000), while external integration variables were designed adapting the internal integration variables to a supply chain relationship. 
Construct validity was established by testing whether the items in a scale all loaded on a common factor when within-scale factor analysis was run. Appendix B shows that all eigenvalues exceeded the threshold of 1,0, which supports each scale's dimensionality.

Table 3. Model measurement and correlation matrix

\begin{tabular}{ccccc}
\multicolumn{4}{c}{ MODEL MEASUREMENT AND CORRELATION MATRIX } \\
\hline \hline SCALE & $\mathbf{1}$ & $\mathbf{2}$ & $\mathbf{3}$ & $\mathbf{4}$ \\
1. IILP &, 9436 & & & \\
2. IILM &, $5884^{* *}$ &, 9553 & & \\
3.R1IE &, $4839^{* *}$ &, $3803^{* *}$ &, 9643 & \\
4. R2IE &, $3765^{* *}$ &, $3155^{*}$ &, $7433^{* *}$ &, 9472 \\
\hline
\end{tabular}

Cronbach's $\alpha$ are in italics on the diagonal.

** significant at $\mathrm{P}<0,01$.

* significant at $P<0,05$.

\subsection{Cluster analysis}

Cluster analysis was used to determine the stages of integration of the Spanish food manufacturers. A K-means cluster analysis was used. This non-hierarchical algorithm requires the researcher to determine the number of groups to obtain. The most appropriate number of clusters was determined using a split-half analysis. We selected a four-cluster option as the starting point for the split-half analysis (theoretically there can be four combinations of the Logistics-Production and Logistics-Marketing integration levels, see Figure 1) and tested four-, three- and two-cluster models. The three-cluster solutions in each of the two split-halves shared the most similarities. But, the decision to employ a three-cluster model was also based on interpretability. Moving from four- to three- cluster solution combined similar clusters, whereas moving from three- to two-cluster solution forced together dissimilar clusters. Also, as it can be 
appreciated in Figure 3, it seems that the three-cluster model is the most suitable one.

Table 4 shows the results of the cluster analysis.

Figure 3. Dispersion graphic and intuitive clusters

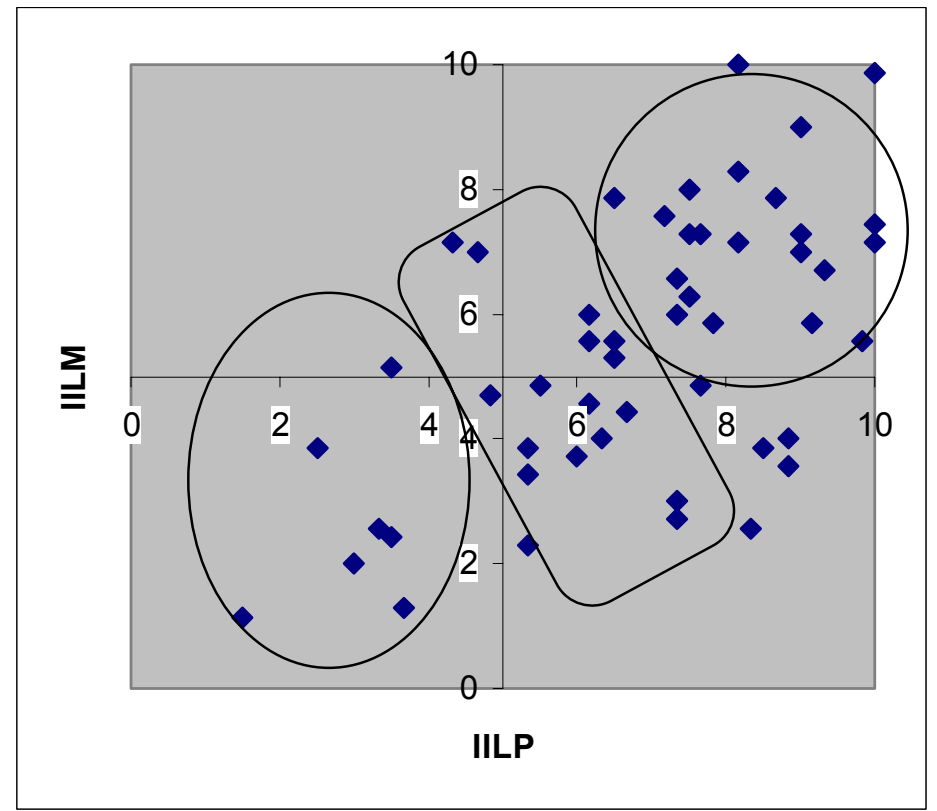

Table 4. Cluster analysis

\begin{tabular}{lcccc}
\hline CLUSTER ANALYSIS & \multicolumn{1}{l}{} \\
\hline \hline FOUR-CLUSTER MODEL & $\mathbf{1}$ & $\mathbf{2}$ & $\mathbf{3}$ & $\mathbf{4}$ \\
\hline IILP & 6,05 & 3,26 & 8,73 & 7,13 \\
IILM & 5,99 & 2,22 & 7,61 & 3,74 \\
Number of cases & 14 & 7 & 17 & 13 \\
\hline \hline THREE-CLUSTER MODEL & $\mathbf{1}$ & $\mathbf{2}$ & $\mathbf{3}$ & \\
\hline IILP & 8,48 & 3,29 & 6,63 & \\
IILM & 7,50 & 2,59 & 4,63 & \\
Number of cases & 20 & 8 & 23 & \\
\hline TWO-CLUSTER MODEL & $\mathbf{1}$ & $\mathbf{2}$ & & \\
\hline IILP & 7,91 & 5,03 & & \\
IILM & 6,71 & 3,29 & & \\
Number of cases & 32 & 19 & & \\
\hline \hline
\end{tabular}


To validate the results of the cluster analysis we ran a discriminant analysis (see Table

5). The discriminant analysis classified $98 \%$ of the companies as the cluster analysis did, indicating extremely good differentiation and a correct classification.

Table 5. Discriminant analysis

\section{DISCRIMINANT ANALYSIS}

\begin{tabular}{lccccc}
\hline \hline & $\begin{array}{c}\text { Initial number } \\
\text { of cases }\end{array}$ & \multicolumn{2}{c}{$\begin{array}{c}\text { Predicted group } \\
\text { membership }\end{array}$} & Total \\
\hline Number & $\mathbf{1}$ & 20 & $\mathbf{2}$ & $\mathbf{3}$ & \\
& $\mathbf{2}$ & 0 & 8 & 0 & 20 \\
& $\mathbf{3}$ & 1 & 0 & 22 & 23 \\
\hline$\%$ & $\mathbf{1}$ & 100 & 0 & 0 & 100 \\
& $\mathbf{2}$ & 0 & 100 & 0 & 100 \\
& $\mathbf{3}$ & 4,3 & 0 & 95,7 & 100 \\
\hline
\end{tabular}

Percent of "grouped" cases correctly classified: $98 \%$.

\section{Results}

\subsection{Internal integration}

The cluster analysis has revealed that, according to the internal integration stage achieved, there are three different groups of companies in the Spanish food sector (see Figure 4). Cluster 1 is made of firms with a high level of internal integration in both interfaces: Logistics-Marketing and Logistics-Production (being higher in this latter interface). In cluster 2 companies have a low level of internal integration in both interfaces, while in cluster 3 firms have a low-medium level of integration in the Logistics-Marketing interface while a medium-high level of integration in the LogisticsProduction interface. 
Figure 4. Clusters identified with the K-means method

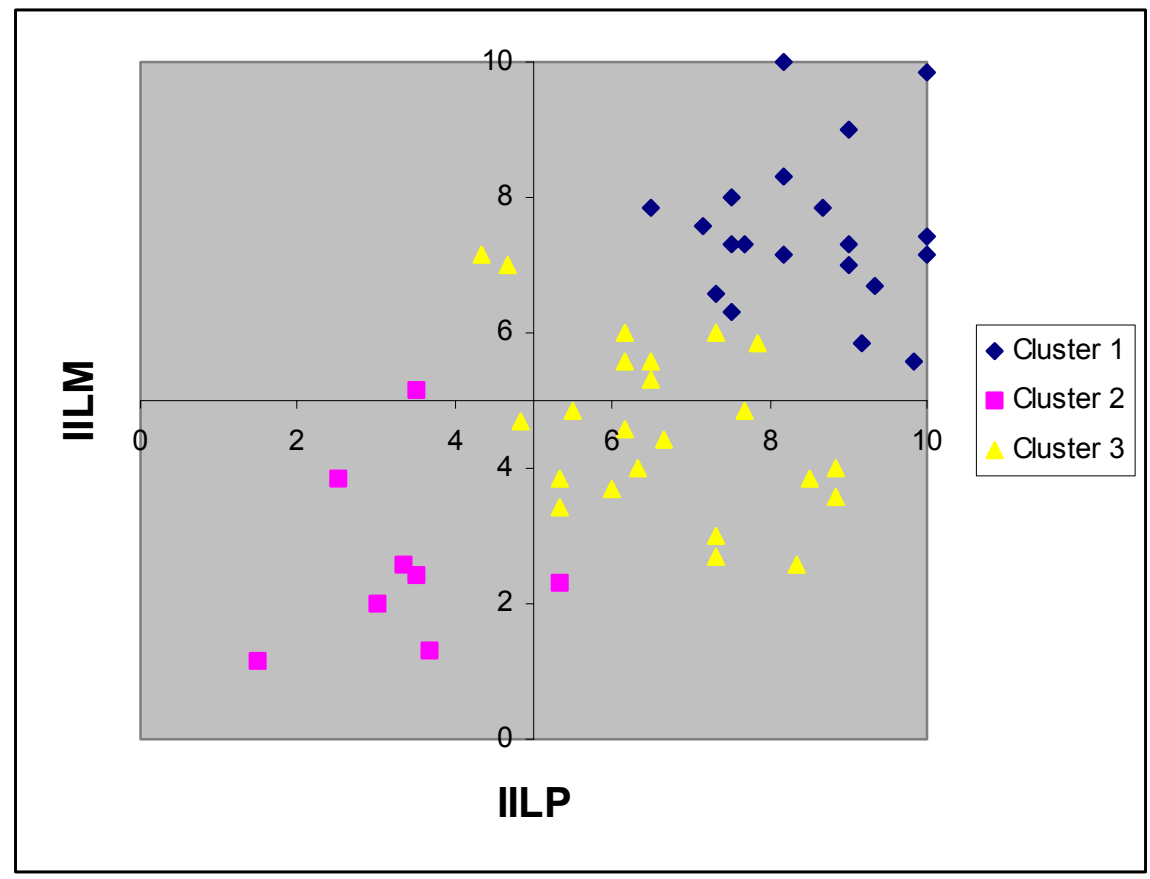

Table 6 summarises the mean values of the items and scales for each one of the clusters. As it can be appreciated, IILP1 (Informal team work with people from the Logistics and Production departments) has a value higher than five in all the clusters. This means that despite not being integrated in the Logistics-Production interface, people from both functional areas work together as an informal team. When there is no integration in the Logistics-Production interface both functional areas do not share ideas, information or other resources; there is neither a joint planning to anticipate and resolve operative problems and neither a joint establishment of objectives, responsibilities or decisions about ways to improve cost efficiencies ... Therefore, what is the role of these informal teams? Further research should investigate the role and aims of these informal teams.

As it can be appreciated in Figure 4 and Table 6, integration in the Logistics-Production interface is always higher than the integration in the Logistics-Marketing interface. This 
could be due to the fact that in Spain Logistics has traditionally been considered an area within the Operations domain.

Analysing the clusters where there is some integration (clusters 1 and 3 ), it can be appreciated that in both interfaces (the Logistics-Production and the LogisticsMarketing), the items that have obtained a higher rate among their scales have been II4 (IILP4 and IILM4) (see Table 6). This means that the aspect on which these three functional areas collaborate most is in the "joint planning to anticipate and resolve operative problems". Other items with a high rate in the integration evaluation are II7 (IILP7 and IILM7): "Joint decisions about ways to improve cost efficiencies". Among the items with a lower rate within their scales, we can find II5 (IILP5 and IILM5): "Joint establishment of objectives". These findings suggest that these three functional areas may collaborate more in the operational aspects than in the strategical ones; however, further research should investigate this result.

The findings also suggest that there can be integration in the Logistics-Production interface despite not being integrated in the Logistics-Marketing interface. However, without Logistics-Production integration there cannot be integration in the LogisticsMarketing interface. Also, the existence of the "NO Logistics-Production, NO LogisticsMarketing"-, the "Logistics-Production, NO Logistics-Marketing"- and the "LogisticsProduction, Logistics-Marketing"- clusters suggests that companies may follow an integration process where they integrate first in the Logistics-Production interface and then in the Logistics-Marketing interface (see Figure 5). 
Table 6. Descriptive statistics by cluster

\begin{tabular}{|c|c|c|c|c|c|c|}
\hline \multicolumn{7}{|c|}{ DESCRIPTIVE STATISTICS BY CLUSTER } \\
\hline & \multicolumn{2}{|c|}{ Cluster 1} & \multicolumn{2}{|c|}{ Cluster 2} & \multicolumn{2}{|c|}{ Cluster 3} \\
\hline & Mean & Sd deviation & Mean & Sd deviation & Mean & Sd deviation \\
\hline \multicolumn{7}{|c|}{ INTERNAL INTEGRATION LOGISTICS-PRODUCTION } \\
\hline $\begin{array}{l}\text { IILP1 } \\
\text { (not included in the IILP scale) }\end{array}$ & 7,85 & 2,13 & 5,75 & 2,60 & 6,70 & 1,79 \\
\hline IILP2 & 8,15 & 1,90 & 3,75 & 1,39 & 6,87 & 1,66 \\
\hline IILP3 & 8,10 & 1,33 & 3,63 & 2,00 & 6,22 & 1,98 \\
\hline IILP4 & 8,95 & 1,00 & 3,38 & 1,30 & 7,39 & 1,53 \\
\hline IILP5 & 8,20 & 1,96 & 2,50 & 0,76 & 6,09 & 1,95 \\
\hline IILP6 & 8,65 & 1,31 & 3,38 & 1,19 & 6,57 & 1,53 \\
\hline IILP7 & 8,85 & 1,84 & 3,13 & 1,55 & 6,65 & 1,70 \\
\hline IILP (Scale) & 8,48 & 1,07 & 3,29 & 1,09 & 6,63 & 1,32 \\
\hline \multicolumn{7}{|c|}{ INTERNAL INTEGRATION LOGISTICS-MARKETING } \\
\hline IILM1 & 7,50 & 1,70 & 3,00 & 2,20 & 5,22 & 1,86 \\
\hline IILM2 & 7,60 & 1,31 & 2,75 & 1,39 & 4,61 & 1,23 \\
\hline IILM3 & 7,15 & 1,42 & 3,00 & 1,51 & 4,30 & 1,66 \\
\hline IILM4 & 8,20 & 1,36 & 2,63 & 1,60 & 4,91 & 1,88 \\
\hline IILM5 & 7,10 & 2,05 & 2,00 & 1,77 & 4,09 & 1,70 \\
\hline IILM6 & 7,45 & 1,85 & 2,13 & 1,73 & 4,39 & 1,92 \\
\hline IILM7 & 7,50 & 1,73 & 2,63 & 1,77 & 4,91 & 1,38 \\
\hline IILM (Scale) & 7,50 & 1,15 & 2,59 & 1,33 & 4,63 & 1,27 \\
\hline \multicolumn{7}{|c|}{ EXTERNAL INTEGRATION MOST COLLABORATING RELATIONSHIP } \\
\hline R1EI1 & 6,20 & 2,48 & 3,63 & 2,56 & 5,26 & 1,98 \\
\hline R1EI2 & 7,30 & 2,45 & 4,00 & 2,27 & 5,70 & 2,84 \\
\hline R1EI3 & 6,85 & 2,58 & 4,13 & 2,70 & 5,52 & 2,54 \\
\hline R1EI4 & 6,20 & 2,75 & 2,88 & 2,36 & 4,96 & 2,88 \\
\hline R1EI5 & 6,80 & 2,26 & 3,75 & 2,25 & 5,35 & 2,59 \\
\hline R1EI6 & 6,10 & 2,90 & 2,88 & 1,96 & 4,22 & 2,88 \\
\hline R1EI7 & 6,15 & 2,87 & 2,75 & 1,98 & 4,96 & 2,48 \\
\hline R1El8 & 6,35 & 3,01 & 3,63 & 2,07 & 4,70 & 2,93 \\
\hline R1El (Scale) & 6,49 & 2,41 & 3,45 & 1,85 & 5,08 & 2,31 \\
\hline \multicolumn{7}{|c|}{ EXTERNAL INTEGRATION LEAST COLLABORATING RELATIONSHIP } \\
\hline R2EI1 & 3,20 & 1,94 & 1,50 & 1,07 & 2,52 & 1,78 \\
\hline R2EI2 & 3,50 & 2,12 & 1,63 & 0,92 & 2,30 & 1,43 \\
\hline R2EI3 & 3,65 & 2,28 & 2,13 & 0,83 & 2,26 & 1,60 \\
\hline R2EI4 & 2,95 & 2,04 & 1,13 & 0,35 & 2,04 & 1,74 \\
\hline R2EI5 & 3,25 & 1,74 & 1,38 & 0,52 & 2,35 & 1,77 \\
\hline R2EI6 & 3,00 & 1,65 & 1,38 & 0,52 & 1,74 & 1,36 \\
\hline R2El7 & 3,15 & 1,73 & 1,50 & 0,53 & 2,52 & 2,13 \\
\hline R2El8 & 3,25 & 2,15 & 1,38 & 0,74 & 1,83 & 1,34 \\
\hline R2El (Scale) & 3,24 & 1,59 & 1,50 & 0,42 & 2,20 & 1,46 \\
\hline
\end{tabular}


Figure 5. Three internal integration stages model

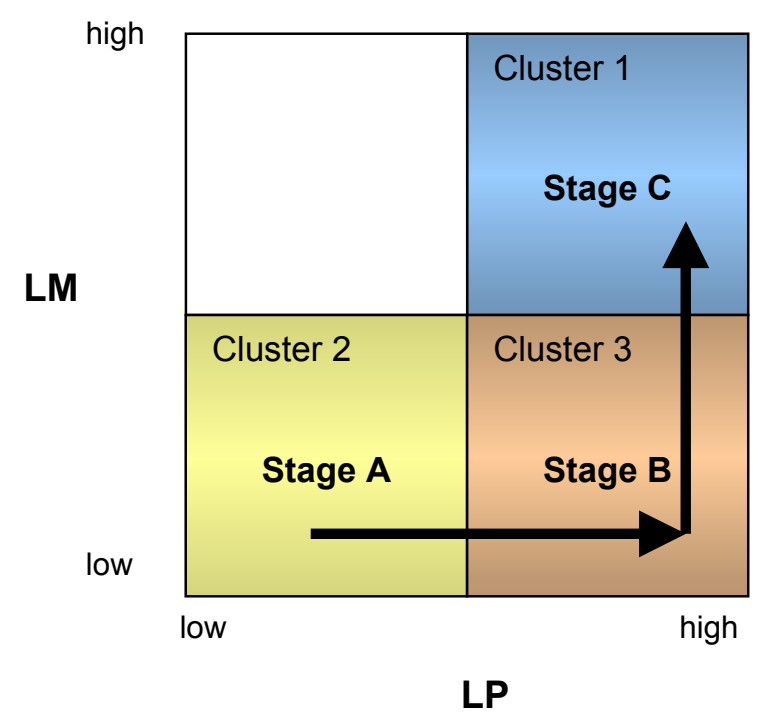

\subsection{External integration}

Regarding external integration for the most integrated relationship (Relationship 1), we can appreciate that the item that has obtained a highest rate is R1El2 "Shared information about sales forecasts, sales and stock levels". This suggests that the way supply chain partners collaborate most is through the sharing of information.

How are firms approaching external integration? Do companies in each one of the three internal integration stages establish collaborating relationships with other supply chain members? Table 7 summarises the results of the integration levels of Relationship 1 (the most collaborating relationship) and Relationship 2 (the least collaborating relationship). In order to determine if a relationship is an externally integrated relationship it needs to have a rate of five or higher in its external integration scale, otherwise it is classified as a non-integrated relationship. 
Table 7. Supply chain relationships by cluster

\begin{tabular}{|l|c|c|}
\hline \multicolumn{3}{|c|}{ SUPPLY CHAIN RELATIONSHIPS BY CLUSTER } \\
\hline \hline & Integrated relationships & Non-integrated relationships \\
\hline \multicolumn{3}{|c|}{ Cluster 1 (IILP, IILM) } \\
\hline R1 & $15(75 \%)$ & $5(25 \%)$ \\
\hline R2 & $4(20 \%)$ & $16(80 \%)$ \\
\hline \multicolumn{3}{|c|}{ Cluster 2 (NO IILP, NO IILM) } \\
\hline R1 & $1(12,5 \%)$ & $7(87,5 \%)$ \\
\hline R2 & $0(0 \%)$ & $8(100 \%)$ \\
\hline \multicolumn{3}{|c|}{ Cluster 3 (IILP, NO IILM) } \\
\hline R1 & $10(43,48 \%)$ & $13(56,52 \%)$ \\
\hline R2 & $2(8,70 \%)$ & $21(91,3 \%)$ \\
\hline
\end{tabular}

Table 7 shows that in cluster 1, fifteen companies had an externally integrated relationship in their most collaborating relationship (R1), and among these companies, four had also an integrated relationship in their least collaborating relationship (R2). In cluster 2, only one company had an integrated relationship and it was in its most collaborating relationship (R1). And finally, in cluster 3 , ten firms had an externally integrated relationship in their most collaborating relationship (R1), and among these ten companies only two had also an externally integrated relationship in their least collaborating relationship (R2). These findings and the values of the scales R1EI and R2El in Table 6 suggest:

1. Companies in cluster 1 (fully internally integrated) have a higher level of external integration than companies in clusters 2 and 3 (see the values of the scales R1El and R2El in Table 6, and the percentages of integrated relationships in R1 and R2 in Table 7). Companies fully internally integrated 
(cluster 1) also have externally integrated relationships with their least collaborating retailers. In cluster 3 (firms integrated only in the LogisticsProduction interface), there are also some companies with externally integrated relationships with their least collaborating customers, but less than in cluster 1 . These findings support for hypothesis H2a: Companies adopting a full internal integration strategy (Option 4: Integration in the Logistics-Production and Logistics-Marketing interfaces) will have the highest levels of external integration.

2. There is a very low level of external integration in companies with a low level of internal integration in both internal interfaces: Logistics-Production and Logistics-Marketing (cluster 2). The scale values for R1EI and R2EI in Table 6 are below five, and the percentages of integrated relationships in R1 and R2 in Table 7 are also very low. These results support for hypothesis H2c: Companies adopting a low internal integration strategy (Option 1: Low internal integration in the Logistics-Production and Logistics-Marketing interfaces) will have the lowest levels of external integration.

3. Hypothesis $\mathrm{H} 2 \mathrm{~b}$, that companies adopting either a Logistics-Production (Option 2) or a Logistics-Marketing (Option 3) integration strategy have medium levels of external integration, was partially supported, as this hypothesis could not be tested for companies integrated only in the Logistics-Marketing interface. Companies only integrated in the Logistics-Production interface (cluster 3 Option 2) have a medium level of external integration. Values of R1El and R2EI of cluster 3 in Table 6 are between the values of R1El and R2El of clusters 1 (full internal integration) and 2 (no internal integration). Also, the percentages of integrated relationships of cluster 3 are between the percentages of clusters 1 and 2 . 
4. The positive correlations between internal and external integration (see Table 3) imply that they influence each other. Internal collaboration may influence external collaboration and vice versa. The influence of external collaboration on internal collaboration has to be understood as an incentive to internal integration: if firms want to collaborate with external customers and suppliers, they need to enhance internal integration. The low level of external integration of non-internally integrated companies, and the fact that the higher the level of internal integration the higher the level of external integration, suggest that firms first internally integrate and then extend the collaboration to other supply chain members. This supports $\mathrm{H} 1 \mathrm{a}$ and rejects $\mathrm{H} 1 \mathrm{~b}$.

Figure 6 summarises these findings. It shows that the integration process that Spanish food manufacturers are following consists of three sequential stages. First, is stage $A$, where there is no integration. Second, is stage B where there is a medium-high level of integration in the Logistics-Production interface, a low-medium level of internal integration in the Logistics-Marketing interface and a medium level of external integration. And finally, is stage C, where companies increase their level of internal integration in both internal interfaces (Logistics-Production and Logistics-Marketing) and increase also their level of external integration. 
Figure 6. Three integration stages model

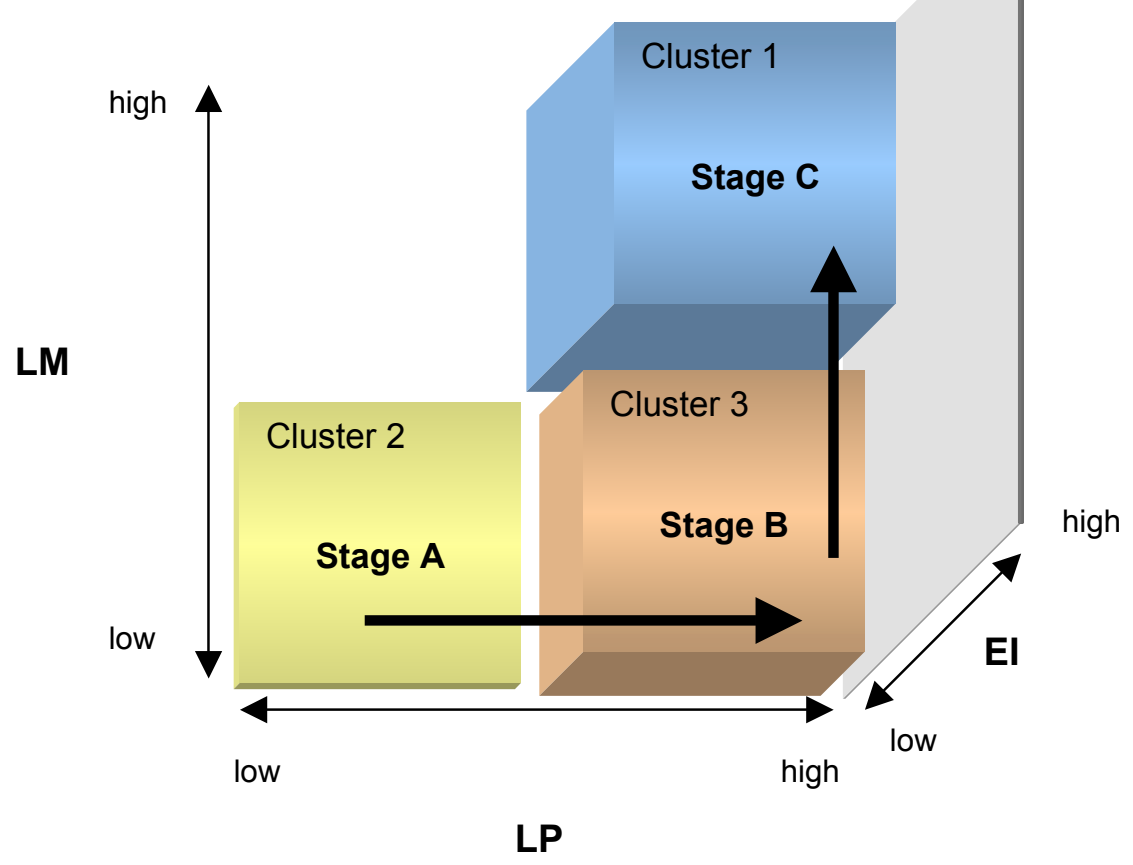

\section{Conclusions and managerial implications}

Only $30 \%$ of the companies in the sample have implemented SCM (there are only fifteen companies in cluster 1 which have externally integrated relationships). However, there are many companies in their way to implement it. Firms have realised that enhanced competitiveness requires that companies ceaselessly integrate within a network of organizations - firms ignoring this challenge are destined to fall behind their rivals.

As their future survival lies on integration, a good understanding of the integration process is a key aspect. And, in this area, our study has a main implication for managers pursuing integration: in the integration process, firms must achieve a relatively high level of collaboration among internal functions before initiating any external integration. A prerequisite for successful SCM is internal integration (Lambert, Cooper \& Pagh, 1998). Internal integration refers to the collaboration and coordination of Logistics with other functional areas, such as Production and Marketing. Such 
collaboration and coordination means that these functional areas must have formal teamwork and share ideas, information and other resources. Integration also means that there is a joint planning to anticipate and resolve operative problems, a joint establishment of objectives, a joint development of the responsibilities' understanding and a joint establishment of decisions about ways to improve cost efficiencies.

Managers pursuing integration have to take actions to promote this sharing of information and joint planning. These actions cover a wide range of aspects: first, there is the need to change the organisational structure, including (1) the establishment of the key business processes to be managed by formal cross-functional workteams and (2) the modification of the criteria on which functional managers are evaluated. One way to coordinate activities within the firm is to identify the key business processes and manage them using cross-functional teams. Cooper, Lambert \& Pagh (1997) extensively describe the key business processes that could be linked across the firm and the supply chain. Another way to promote integration is to change the criteria on which managers are evaluated. Gimenez (2003) describes some examples where a wrong manager evaluation system led to cost-inefficient purchasing decisions (in terms of total cost of ownership).

Second, there is the need to train people on the benefits that integration can bring. Change management and people training play a key role in an integration process, as they are crucial to minimise the barriers to implementing SCM.

Our study suggests that Spanish food manufacturers seem to initiate integration by coordinating Logistics and Production. As stated before, this might be due to the fact that, in Spain, Logistics has been considered an area under the Operations and Production domain. This finding does not imply that companies have to implement SCM by integrating first in this interface. Firms should initiate integration in the interface 
where it is easier and where integration benefits can be obtained early. This will encourage further integration efforts.

The results also show that the highest levels of external integration are associated to companies with the highest levels of integration in the Logistics-Production and Logistics-Marketing interfaces. This implies that although integration has been started only in the Logistics-Production interface, when higher levels of external integration are pursued, there is the need to integrate also in the Logistics-Marketing interface. Therefore, managers pursuing supply chain integration need to pay attention to all internal interfaces.

Another implication for managers is how to approach external integration. The results have shown that sharing of information (about sales, sales forecasts and stocks) and joint planning and development of logistics processes play again a key role in the integration process. This implies that there is the need to move from an arm's length type of relationships to a more partnership approach, where trust and sharing of information are vital.

Our study has contributed to the existing knowledge by providing a description of how Spanish food manufacturers are approaching integration. However, our paper has some limitations: first, in the analysis of external integration, it has only considered one side of the manufacturer-retailer relationship. And, second, due to the reduced number of cases in each cluster, a statistical comparison of means to analyse the integration differences has not been possible.

Further research should investigate the integration processes in other industries and countries. It should also consider other internal interfaces, such as LogisticsPurchasing and Production-Purchasing, and investigate the business processes that are critical and/or beneficial to integrate and manage within and between firms. 


\section{References}

Anderson, J. \& Narus, J., 1991. "Partnering as a focused market strategy", California Management Review, Spring, pp. 95-113.

Armstrong, J.S. \& Overton, T.S., 1977. "Estimating non-response bias in mail surveys", Journal of Marketing Research, Vol.14 No.3, pp. 396- 402.

Byrne, S.M. \& Javad, S., 1992. "Integrated Logistics Information Systems (ILIS): Competitive advantage or increased cost”, Council of Logistics Management Annual Conference Proceedings, Oak Brook, Illinois, pp. 55-73.

Casanovas, A. \& Cuatrecasas, LI., 2001. Logística Empresarial, Ed. Gestion 2000, Barcelona.

Christiansee, E. \& Kumar, K., 2000. "ICT-enabled coordination of dynamic supply webs", International Journal of Physical Distribution and Logistics Management, Vol.30 No.3/4, pp. 268-285.

Christopher, M., 1998. Logistics and Supply Chain Management: Strategies for reducing cost and improving service, Financial Times Pitman Publishing, London.

Cooper, M.C. \& Gardner, J., 1993. "Building good business relationships - More than just partnering or strategic alliances", International Journal of Physical Distribution and Logistics Management, Vol 23 No 6, pp. 14-26.

Cooper, M.C., 1993. "International Supply Chain Management: Implications for the bottom line", Proceedings of the Society of Logistics Engineers, Society of Logistics Engineers, Hyattsville. 
Cooper, M.C., Lambert, D.M. \& Pagh, J.D., 1997. "Supply Chain Management: More than a new name for Logistics", The International Journal of Logistics Management, Vol 8 No 1, pp. 1-13.

Copacino, W.C., 1990. "Purchasing strategy for the 90's", Traffic Management, Vol 29 No 10, pp. 67.

Daugherty, P.J., Ellinger, A.E. \& Rogers, D., 1995. “Information accessibility: Customer responsiveness and enhanced performance", International Journal of Physical Distribution and Logistics Management, Vol.25 No.1, pp. 4-17.

Daugherty, P.J., Sabath, R.E. \& Rogers, D.S., 1992. "Competitive advantage through customer responsiveness", Logistics and Transportation Review, Vol.28 No.3, pp. 257271.

Dyer, J.; Cho, D. \& Chu, W., 1998. "Strategic supplier segmentation: The next best practice in supply chain management", California Management Review, Vol 40 No 2, pp. 57-78.

Ellinger, A.E., Daugherty, P.J. \& Keller, S., 2000. "The relationship between marketing/ logistics interdepartmental integration and performance in U.S. manufacturing firms: An empirical study", Journal of Business Logistics, Vol.21 No.1, pp. 1-22.

Ellinger, A.E., Taylor, J.C. \& Daugherty, P.J., 2000. "Programas de reposición automática y niveles de involucramiento: Su impacto en la performance", The International Journal of Logistics Management, Vol.10 No.1, pp. 29-40.

Ellram, L.M. \& Cooper, M.C., 1993. "The relationship between supply chain management and Keiretsu", The International Journal of Logistics Management, Vol.4 No.1, pp. 1-12. 
Fox, R.J., Crask, M. \& Kim, J., 1988. "Mail survey response rate: A Metaanalysis of selected techniques for inducing response", Public Opinion Quarterly 52 No.1, pp. 467491.

Gimenez, C. \& Ventura, E., 2003. "Supply Chain Management as a competitive advantage in the Spanish grocery sector", The International Journal of Logistics Management, Vol.14 No.1.

Gimenez, C. \& Ventura, E., 2003b. "Logistics-Production, Logistics-Marketing and external integration: Their impact on performance". UPF Working Paper \# 657.

Gimenez, C., 2003. "Supply Chain Management Implementation in the Spanish Grocery Sector: An Exploratory Study". UPF Working Paper \# 668.

Groves, G. \& Valsamakis, V., 1998. "Supplier-customer relationships and company performance". The International Journal of Logistics Management, Vol.9 No.2, pp. 5163.

Gustin, C.M.; Stank, T.P. \& Daugherty, P.J., 1994. "Computerization: Supporting integration", The International Journal of Physical Distribution and Logistics Management, Vol.24 No.1, pp. 11-16.

Kraljic, P., 1983. "Purchasing must become supply management", Harvard Business Review, Vol 61, pp. 109-117.

Lambert, D.M. \& Harrington, T.C., 1990. "Measuring nonresponse in customer service mail surveys", Journal of Business Logistics, Vol.11 No.2, pp. 5-25.

Lambert, D.M., Cooper, M.C. \& Pagh, J.D., 1998. "Supply Chain Management: Implementation issues and research opportunities", The International Journal of Logistics Management, Vol.9 No.2, pp. 1-19. 
Larson, P.D., 1994. "An empirical study of inter-organizational functional integration and total costs", Journal of Business Logistics, Vol.15 No.1, pp. 153-169.

Masella, C. \& Rangone, A., 2000. "A contingent approach to the design of vendor selection systems for different types of cooperative customer/supplier", International Journal of Operations and Production Management, Vol 20 No 1, pp. 70-84.

Scannell, T.V., Vickery, S.K. \& Dröge, C.L., 2000. "Upstream supply chain management and competitive performance in the automotive supply industry", Journal of Business Logistics, Vol.21 No.1, pp. 23-48.

Scott, C. \& Westbrook, R., 1991. "New strategic tools for supply chain management", International Journal of Physical Distribution and Materials Management, Vol.21 No.1, pp. 23-33.

Shapiro, R.D., 1984. "Get leverage from logistics", Harvard Business Review, Vol.62 no.3, pp. $119-126$.

Stank, T.P., Crum, M. \& Arango, M., 1999. "Benefits of inter-firm coordination in food industry supply chains", Journal of Business Logistics, Vol.20 No.2, pp. 21-41.

Stank, T.P., Daugherty, P.J. \& Autry, C.W., 1999. "Collaborative planning: Supporting automatic replenishment programs". Supply Chain Management, Vol.4 No.2, pp. 75-85.

Stank, T.P., Daugherty, P.J. \& Ellinger, A.E., 2000. “Integración Marketing/Logística y performance de la empresa", The International Journal of Logistics Management, Vol.10 No.1, pp 13-27.

Stank, T.P., Keller, S. \& Daugherty, P.J., 2001. "Supply chain collaboration \& logistical service performance", Journal of Business Logistics, Vol.22 No.1, pp. 29-48. 
Stevens, G.C., 1989. "Integrating the supply chain", International Journal of Physical Distribution and Materials Management, Vol.19 No.8, pp. 3-8.

Stock, G.N., Greis, N.P. \& Kasarda, J.D., 1998. "Logistics, strategy and structure: A conceptual framework", International Journal of Operations and Production Management, Vol.18 No.1, pp. 37-52.

Tang, C.S., 1999. "Supplier relationship map", International Journal of Logistics: Research and Applications, Vol 2 No 1, pp. 39-56.

The Global Logistics Team at Michigan State University, 1995. World Class Logistics: The challenge of managing continuous change, Council of Logistics Management, Oak Brook, Illinois. 


\section{Appendix}

\section{Appendix A. Exploratory factor analysis}

\begin{tabular}{|c|c|c|c|c|c|}
\hline & \multicolumn{5}{|c|}{ Factors } \\
\hline & 1 & 2 & 3 & 4 & 5 \\
\hline R2EI5 & 896 & 244 & 113 & 101 & \\
\hline R2El7 & 829 & 250 & & 114 & \\
\hline R2EI6 & 824 & 264 & 131 & 167 & \\
\hline R2El8 & 810 & 251 & 235 & & \\
\hline R2EI2 & 793 & 254 & 113 & 139 & \\
\hline R2EI4 & ,772 & 284 & & & 151 \\
\hline R2EI3 & ,736 & ,465 & & & 157 \\
\hline R2El1 & ,576 & 490 & 155 & & 253 \\
\hline R1EI5 & 337 & ,870 & 179 & 141 & \\
\hline R1El3 & 298 & 869 & & 180 & \\
\hline R1El8 & 401 & 850 & & 156 & \\
\hline R1El1 & 139 & 777 & 175 & 117 & 334 \\
\hline R1El7 & 491 & ,757 & 112 & 250 & \\
\hline R1EI6 & 488 & ,712 & 108 & 291 & \\
\hline R1El2 & 396 & ,702 & 268 & 129 &,- 115 \\
\hline R1El4 & 464 & 658 & 191 & 208 & \\
\hline IILM3 & & 271 & 891 & 104 & 162 \\
\hline IILM4 & & & 884 & 222 & \\
\hline IILM6 & 114 & & 878 & 216 & \\
\hline IILM5 & 148 & 244 & 840 & 169 & \\
\hline IILM2 & 178 & & 833 & 335 & \\
\hline IILM7 & 111 & 135 & 804 & 336 & \\
\hline IILM1 & & & 768 & 152 & 448 \\
\hline IILP6 & & 166 & 361 & 835 & \\
\hline IILP4 & 118 & 161 & 285 & 834 & 162 \\
\hline IILP7 & 265 & 238 & 312 & 806 & \\
\hline IILP5 & & ,285 & ,278 & ,802 & \\
\hline IILP3 & 113 & 130 & 229 & ,726 & ,495 \\
\hline IILP2 & 272 & & ,245 & 632 & ,560 \\
\hline IILP1 & & & & 273 & ,874 \\
\hline
\end{tabular}

Principal component analysis. Rotation method: Varimax with Kaiser. 
Appendix B. Within-scale factor analysis

Internal integration Logistics-Production

\begin{tabular}{|l|c|c|}
\hline & & Factor loading \\
\hline & IILP4 &, 916 \\
\hline & ILP6 &, 908 \\
\hline & IILP5 &, 891 \\
\hline & ILP7 &, 881 \\
\hline & IILP3 &, 875 \\
\hline & IILP2 &, 838 \\
\hline Eigenvalue & & \\
\hline Percent of variation & 4,703 & \\
\hline Kaiser-Meyer-Olkin & $78,38 \%$ & \\
\hline Bartlett test of sphericity & 287,714 & \\
\hline Significance &, 000 & \\
\hline
\end{tabular}

Principal component analysis

Internal integration Logistics-Marketing

\begin{tabular}{|l|c|c|}
\hline & & Factor loading \\
\hline & IILM3 &, 934 \\
\hline & IILM2 &, 911 \\
\hline & IILM6 &, 907 \\
\hline & IILM4 &, 903 \\
\hline & IILM5 &, 885 \\
\hline & IILM7 &, 871 \\
\hline & IILM1 &, 824 \\
\hline Eigenvalue & & \\
\hline Percent of variation & 5,561 & \\
\hline Kaiser-Meyer-Olkin & $79,44 \%$ & \\
\hline Bartlett test of sphericity &, 910 & \\
\hline Significance & 354,484 & \\
\hline
\end{tabular}

Principal component analysis 
External integration (relationship 1)

\begin{tabular}{|c|c|c|}
\hline & & Factor loading \\
\hline & R1EI5 &, 954 \\
\hline & R1El8 & ,943 \\
\hline & R1EI7 & ,936 \\
\hline & R1EI3 & ,934 \\
\hline & R1EI6 & ,905 \\
\hline & R1El2 & ,851 \\
\hline & R1EI4 & 851 \\
\hline & R1El1 & ,784 \\
\hline Eigenvalue & 6,432 & \\
\hline Percent of variation & $80,40 \%$ & \\
\hline Kaiser-Meyer-Olkin & ,922 & \\
\hline Bartlett test of sphericity & 488,881 & \\
\hline Significance & ,000 & \\
\hline
\end{tabular}

Principal component analysis

External integration (relationship 2)

\begin{tabular}{|l|c|c|}
\hline & & Factor loading \\
\hline & R2EI5 &, 935 \\
\hline & R2EI6 &, 880 \\
\hline & R2EI7 &, 872 \\
\hline & R2EI3 &, 870 \\
\hline & R2EI8 &, 863 \\
\hline & R2EI2 &, 840 \\
\hline & R2EI4 &, 831 \\
\hline & R2El1 &, 762 \\
\hline Eigenvalue & & \\
\hline Percent of variation & 5,888 & \\
\hline Kaiser-Meyer-Olkin & $73,61 \%$ & \\
\hline Bartlett test of sphericity &, 800 & \\
\hline Significance & 401,364 & \\
\hline
\end{tabular}

Principal component analysis 